\title{
The effects of bauxite, metakaolin, and porosity on the thermal properties of prepared Iraqi clays refractory mortars
}

\author{
Shihab A. Zaidan ${ }^{1} \cdot$ Mustafa H. Omar ${ }^{1}$
}

Received: 7 December 2017 / Accepted: 19 March 2018 / Published online: 21 April 2018

(c) The Author(s) 2018

\begin{abstract}
One of the most important requirements for the manufacture of refractory mortars, especially those used in the construction of thermal systems (building or plastering), is the balance between thermal insulation properties and porosity. Where, increasing porosity of mortar to a large amount may be always undesirable, because the absorption of liquid and gases emitted from industrial system is decline the bonded with bricks and structural properties of mortars. Refractory mortars prepared from either fired bauxite or metakaolin clays with different percentages of kaolin (10, 20, 30, and $40 \mathrm{wt} \%)$. Bauxite rocks were fired at $1200{ }^{\circ} \mathrm{C}$ and metakaolin was obtained by firing kaolin up to $700{ }^{\circ} \mathrm{C}$ then crushed and grinded. Grog was added to mixture to reduce the shrinkage. Cylindrical specimens are prepared and then sintered at $1200{ }^{\circ} \mathrm{C}$. All mixtures maintained a low thermal conductivity within the limits of thermal insulation material (less than $0.5 \mathrm{~W} / \mathrm{m} \mathrm{K}$ ); it was done by controlling the porosity which reached a maximum value approximately $25 \%$. The volumetric heat capacity and thermal diffusivity was ranged between $\left(1-10 \mathrm{MJ} / \mathrm{m}^{3} \mathrm{~K}\right),\left(0.06-0.2 \mathrm{~mm}^{2} / \mathrm{s}\right)$, respectively.
\end{abstract}

\section{Introduction}

Refractories are substances that can be used as a thermal insulation for high temperatures and it can withstand high temperatures without breaking or deformation. It also preserves several of their properties under various operating conditions. Refractory ceramics have special characteristics such as high resistance to thermal shock, high resistance to melting, with low thermal conductivity and a low thermal expansion. Furnace linings wall was considered one of the most important applications of refractory materials [1].

Refractories are generally classified into two types brick and monolithic refractories. Mortars are available in compositions that either approximate the bricks they are holding together, or they are chosen so that their thermal expansion will be comparable to the bricks [2].

In many researches, it has been discussed in the field of refractory mortar and its properties, in 2004, Christianto, and Heru Ari prepared self-compacting mortar using different mineral admixtures. Limestone powder, fly ash, kaolinite, and brick powder were used as mineral admixtures. Workability

Mustafa H. Omar

mustafahassan276@gmail.com

1 Department of Applied Sciences, Materials Science College, University of Technology, Baghdad, Iraq of fresh mortar studied by preparing 43 different mixes of SCM. Results showed that workability increased only with fly ash and limestone powder [3]. In 2006, Al-Amaireh studied the improvement of physical and thermal properties of fire clays produced from bauxite and found that the improvement of this type of refractories had a high strength and hardness. This product can be used in the cement industry [4]. In 2012, Andreev et al studied the compressive behavior of dry joins closure of two types of refractory bricks in a large temperature range. Measurements showed that the stiffness of the material influenced on the stress that needed to close the joints also temperature influenced on the closure of the joints by stiffness changing [5]. In 2015, Mahdi prepared a refractory mortar from fire-clay brick scraps by adding Iraqi kaolin with different percentage contents $(21,27,32,40$, and $47 \%$ ). Disks specimens were used for bulk density, thermal conductivity, specific heat capacity, and bond strength tests. The results showed that the specimens with $40 \%$ kaolin had the best properties [6]. In 2016, Torres and Matias used ceramic residues to form a lime mortar which can be used as a plaster. Mechanical and physical properties for different mortar were studied. Results showed that the ceramic residues mortar had good mechanical properties which made it suitable for plaster repairing [7]. The study aims to prepare a refractory mortar from Iraqi locally clays which can be used for construction 
and plastering the lining furnace walls at temperature up to $1200{ }^{\circ} \mathrm{C}$.

\section{Experimental work}

For preparing the specimens, the kaolin and bauxite rocks were sintered at $1200^{\circ} \mathrm{C}$ and metakaolin was obtained by firing kaolin up to $700{ }^{\circ} \mathrm{C}$ then crushed to a fine powder and finally sieved to different particle sizes $(0.2$ and $1.18 \mathrm{~mm})$. Bauxite and metakaolin were used as additives in $(10,20$, 30 , and $40 \mathrm{wt} \%$ ) of kaolin weight. First, a dry mixing to the kaolin and the additives were done, and then, water $(6 \mathrm{ml})$ and potassium silicate $(4 \mathrm{ml})$ were added as a binding material for the total mix. The specimens were prepared by hand molding method. They pressed in a cylindrical mold with diameter of $(10 \mathrm{~mm})$ and left in the air for $24 \mathrm{~h}$ then fired at $1200{ }^{\circ} \mathrm{C}$ for $1 \mathrm{~h}$. The specimens were prepared according to standard ASTM F1097-91 [8]. The chemical analysis for kaolin, bauxite, and metakaolin rocks used in this research is shown in Table 1 also the block diagram of the experimental work is shown in Fig. 1.

The X-ray diffraction test for kaolin rocks shows that they consist basically of kaolinite and quartz; it is illustrated in Fig. 2. For bauxite rocks, it shows that bauxite rocks consist of kaolinite and boehmite, as illustrated in Fig. 3. While for metakaolin shows that it consists of kaolinite and quartz, as illustrated in Fig. 4.

\section{Test procedure}

\subsection{Apparent porosity and bulk density}

Apparent porosity and bulk density were measured by immersion of specimens in water for a few seconds using Archimedes method. The mass of specimens was measured in the air when suspended in water and when dried. Cylindrical specimens of $(20 \times 10 \mathrm{~mm})$ were used according to ASTM C 20 [9] using the following equations:

Apparent porosity $=[(W-D) /(W-S)] \times 100$,

Bulk density $=D / W-S$,

where $D$ is the dry weight $(\mathrm{g})$, and $W$ is the saturated weight (g) and $S$ weight (g) of dry specimen in the air.

\subsection{Thermal conductivity, volumetric heat capacity, and thermal diffusivity}

In this study, three thermal properties: thermal conductivity, thermal diffusivity, and volumetric heat capacity, which were determined using a transient plane heat source method. The commercial thermal constants analyzer TPS 500 (Hot Disk) was used to determine the thermal properties for cylindrical specimens. The analysis was based on embedding a hot disk probe within a sample, as shown in Fig. 5. The hot disk probe was used as both a heating plate (source) and a dynamic temperature sensor.

An electrical current in the form of a step function was applied to the heating plate to generate a heat pulse for a duration of $20 \mathrm{~s}$. Thermal conductivity $(\lambda)$ and thermal diffusivity $(\alpha)$ values were determined by fitting the increasing temperature curve using least-squares analysis. Consequently, the volumetric heat capacity can be obtained by dividing thermal conductivity by thermal diffusivity (using Eq. 3):

$\alpha=\lambda / C$,

where $C$ is the volumetric heat capacity. The test was done according to ISO 22007-2 [10].

\section{Results and discussion}

\subsection{Apparent porosity and bulk density}

Increase in bulk density leads to a decrease in porosity. The density depends more on raw materials which are used, and also on firing temperature and soaking time. Results showed that there was a decrease in porosity and an increase in density for bauxite additives as shown in Figs. 6 and 8. This is because the mullite phase possesses high density than kaolin, while the porosity increased and density decreased with the addition of metakaolin additives, because the change in phases during firing leads to formation of vacancies in the structure, as shown in Figs. 7 and 9, respectively.

In general, porosity was high and density was low when compared to dense refractories due to the loss on ignition and evaporation of formation water, as well as increasing the space between the particles of powder as a result of hand
Table 1 Chemical analysis for raw materials

\begin{tabular}{lcllllllll}
\hline Raw materials & \multicolumn{1}{l}{ Oxides } & \multicolumn{10}{l}{} & \multicolumn{10}{c}{} \\
\cline { 2 - 9 } & $\mathrm{LOI} \%$ & $\mathrm{~K}_{2} \mathrm{O} \%$ & $\mathrm{Na}_{2} \mathrm{O} \%$ & $\mathrm{MgO} \%$ & $\mathrm{CaO} \%$ & $\mathrm{TiO}_{2} \%$ & $\mathrm{Fe}_{2} \mathrm{O}_{3} \%$ & $\mathrm{Al}_{2} \mathrm{O}_{3} \%$ & $\mathrm{SiO}_{2} \%$ \\
\hline Kaolin & 12.3 & 0.23 & 0.2 & 0.61 & 2.5 & 1.08 & 1.65 & 31.82 & 49.64 \\
Bauxite & 13.75 & - & - & 1.07 & 1.20 & 1.80 & 1.30 & 61.90 & 18.98 \\
Metakaolin & 0.9 & 0.44 & 0.19 & 0.3 & 1.68 & - & 1.21 & 37.31 & 52.38 \\
\hline
\end{tabular}


Fig. 1 Schematic representation of the experimental work

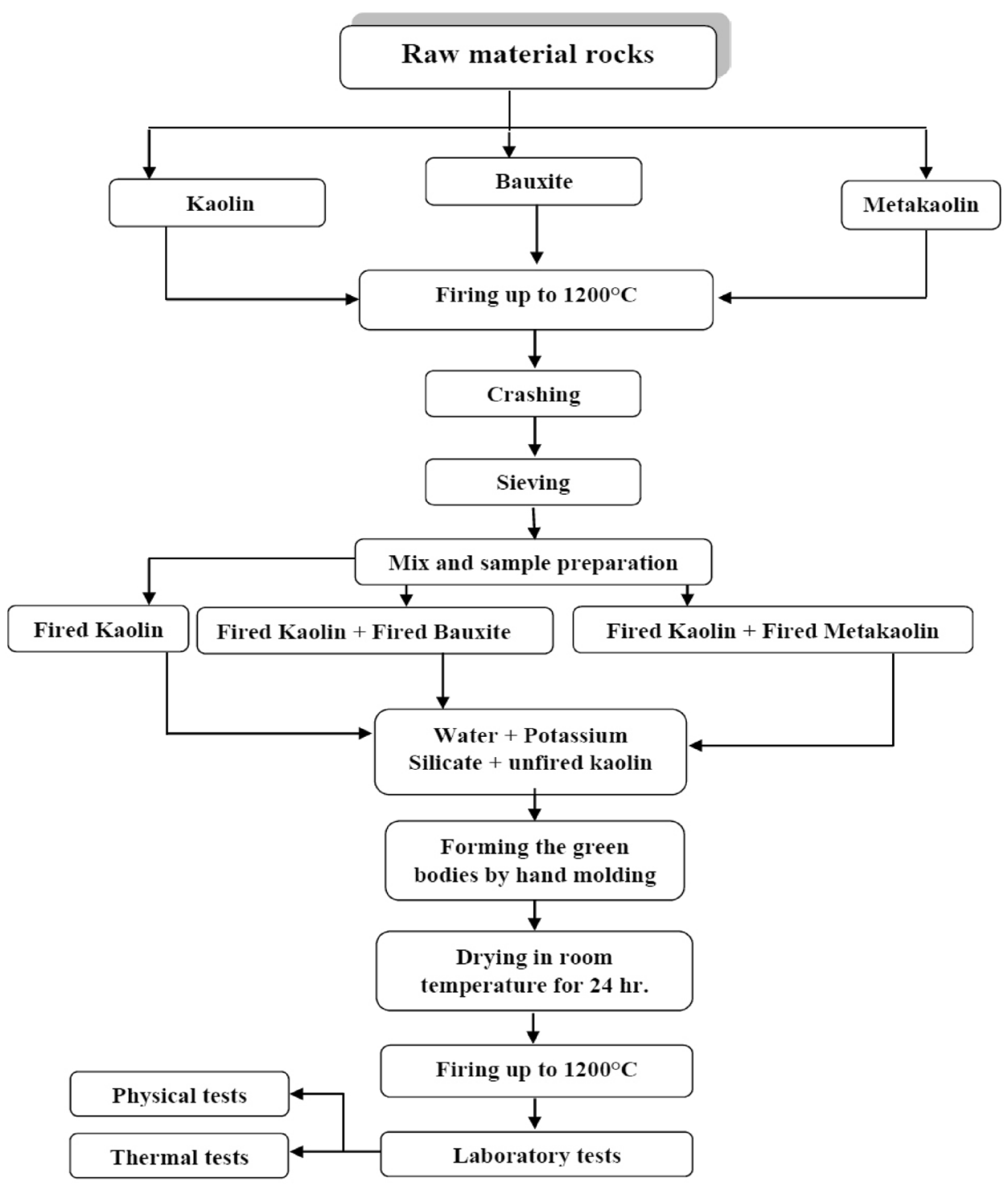

molding. All this leads to a weak stacking between grains after firing.

\subsection{Thermal conductivity}

Thermal conductivity was increased with bauxite additives increases, because the porosity decreases due to glass phase increasing from fluxing oxides, which melt at temperatures below $1200{ }^{\circ} \mathrm{C}$. As well as the main effect of porosity is to reduce thermal conductivity, because porosity acts as a barrier to the flow of heat within the ceramic product while decreasing occurred with increasing metakaolin additives, this decreasing resulted from the high porosity that found with metakaolin additives. The results are shown in Fig. 10. The relation between thermal conductivity and porosity is shown in Figs. 11 and 12. The thermal conductivity was decreased with porosity increases from 0.5 to $0.4 \mathrm{~W} / \mathrm{m} \mathrm{K}$ for bauxite additions and to $0.36 \mathrm{~W} / \mathrm{m} \mathrm{K}$ for metakaolin additions. The effect of porosity is important; when the thermal conductivity of the air is negligible compared to the solid phases, the addition of large volume fractions of pores can dramatically reduce thermal conductivity. This approach is used in the fabrication of insulation refractories. Briefly, the large amount of porosity leads to improved thermal shock resistance of refractory insulating bricks [11].

\subsection{Volumetric heat capacity}

The more measurable volumetric heat capacity the more the amount of heat that required to change the temperature of one unit volume of a material by $1{ }^{\circ} \mathrm{C}$. The increment in volumetric heat capacity with increasing the addition of bauxite and decrement with increasing metakaolin additives is shown in Fig. 13. 


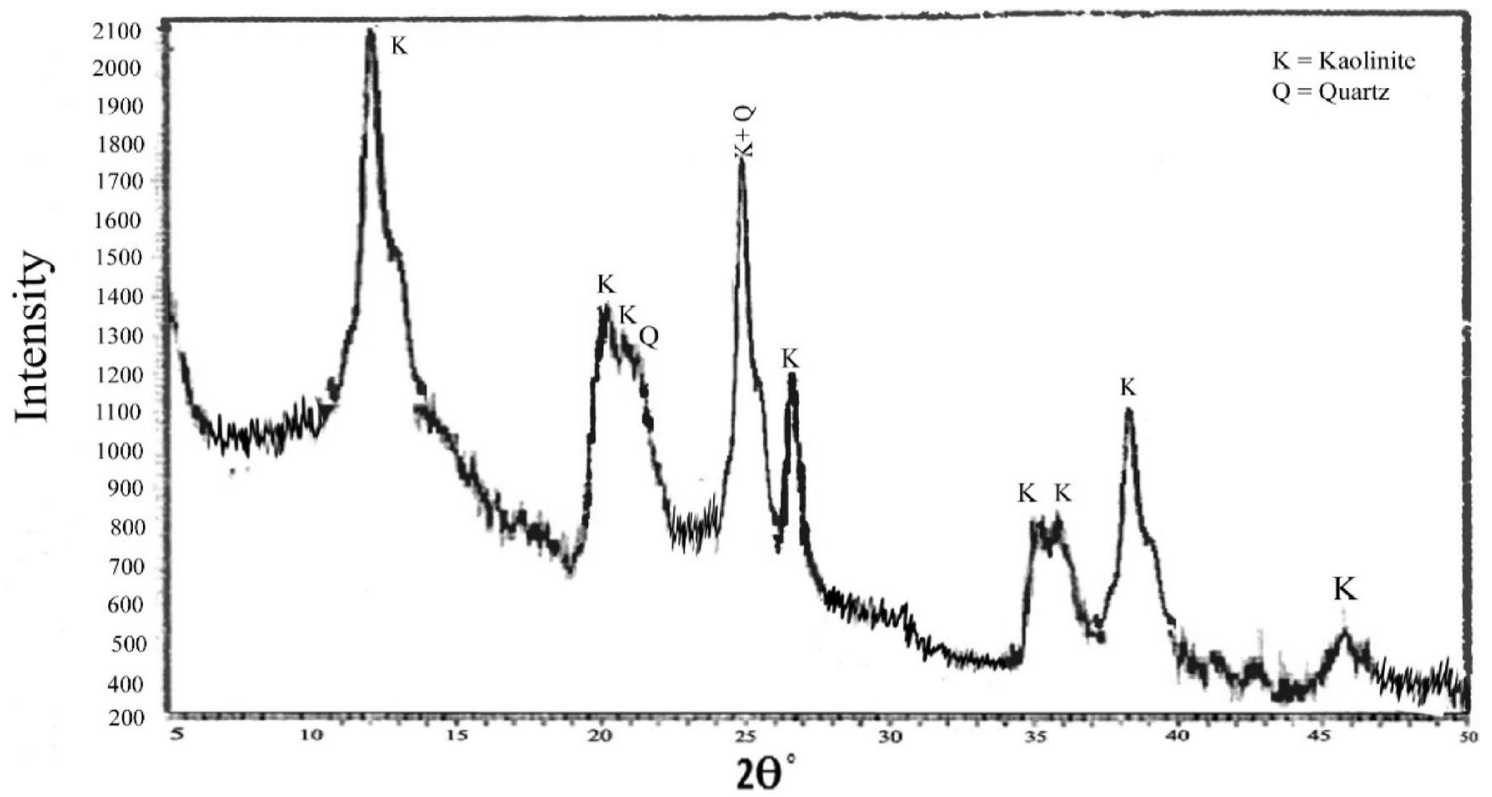

Fig. 2 X-ray diffraction for kaolin

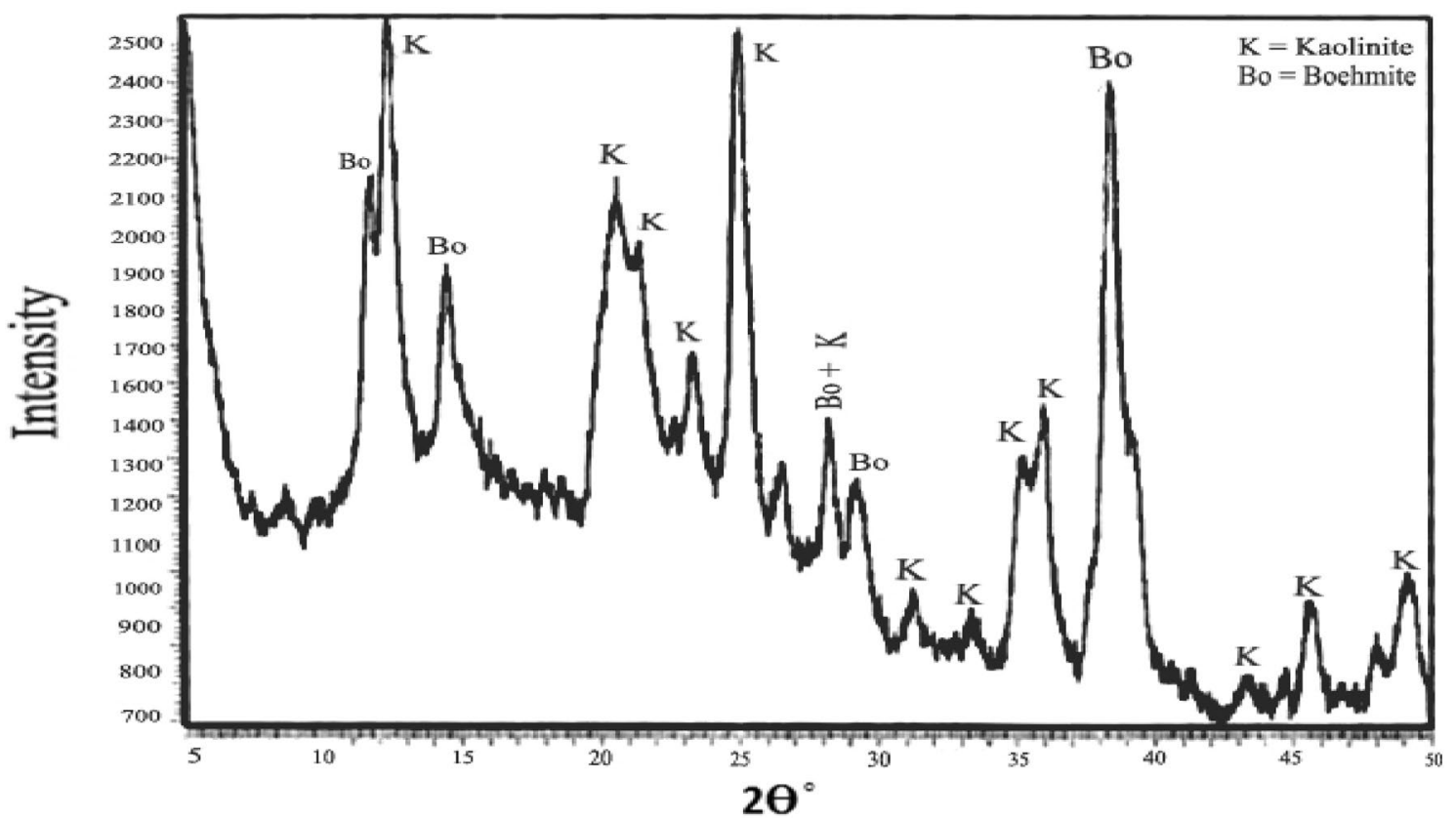

Fig. 3 X-ray diffraction for bauxite

The volumetric heat capacity and thermal conductivity of the specimens are strongly dependent on the ratio of density and porosity. However, addition of bauxite leads to decrease the porosity, as shown in Fig. 6, therefore, that leads to increase in the volumetric heat capacity, while in the case of adding metakaolin, it decreases it. During the firing process, the amount of porosity decreases, whereas at the same time, there is a glass phase formation which fills the pores; this implies an increment in volumetric heat capacity. Figures 14 and 15 show the relation between volumetric heat capacity and porosity.

We can neglect thermal radiation at ordinary temperatures. Then, the heat capacity per unit volume is reduced by the existence of pores, because the heat capacity of pores per 


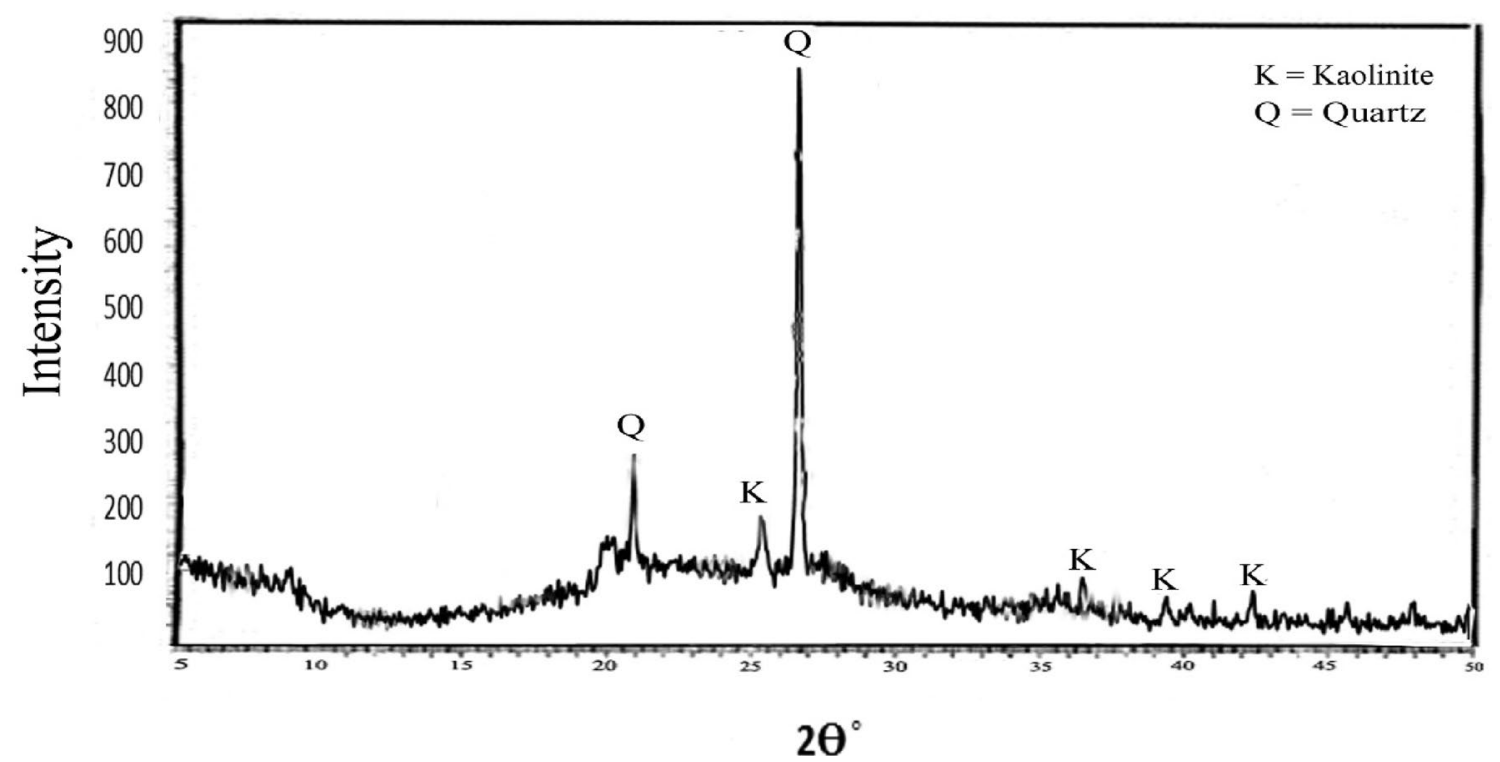

Fig. 4 X-ray diffraction for metakaolin

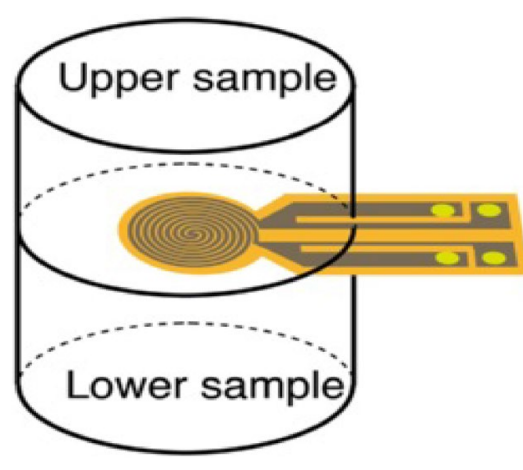

Fig. 5 Hot disk transient plane heat source probe and sample assembly

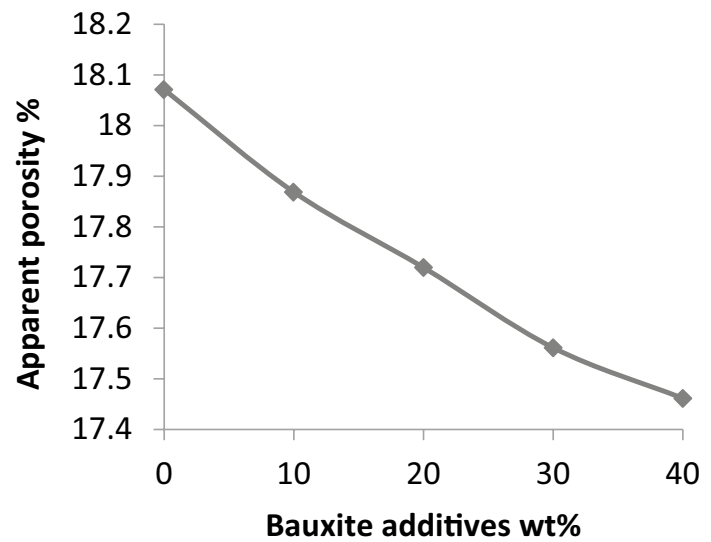

Fig. 6 Apparent porosity of refractory specimens change with different bauxite additions

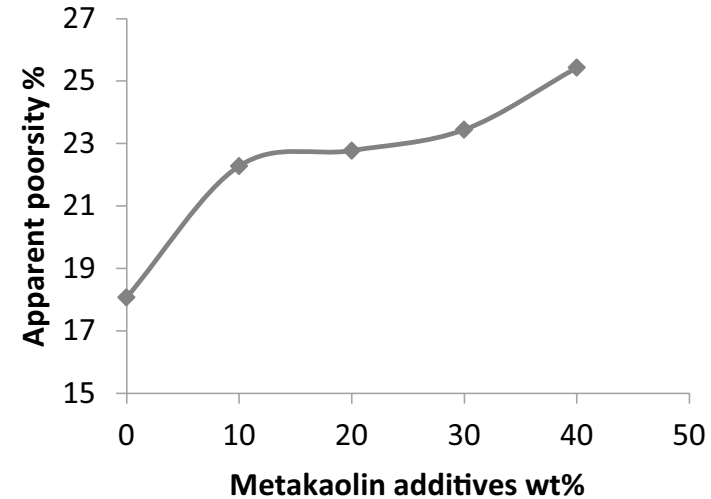

Fig. 7 Apparent porosity of refractory specimens change with different metakaolin additions

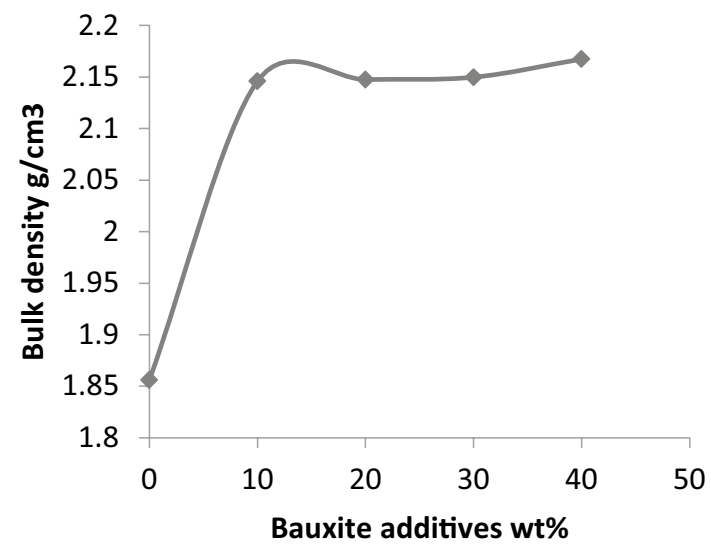

Fig. 8 Bulk density of refractory specimens change with different bauxite additions 


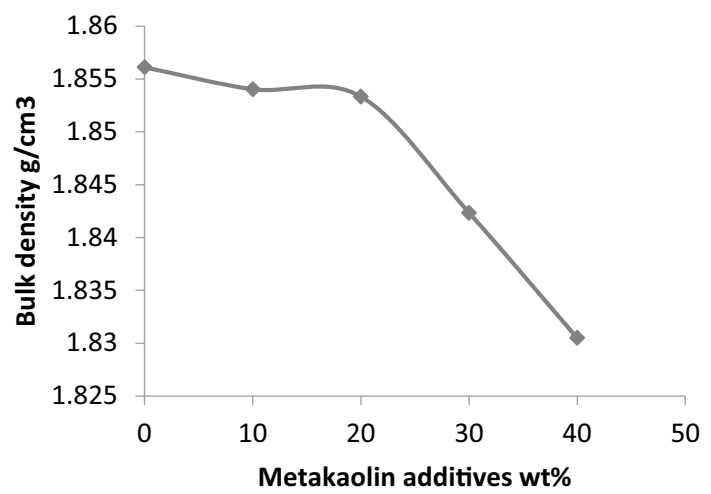

Fig. 9 Bulk density of refractory specimens with different metakaolin additions

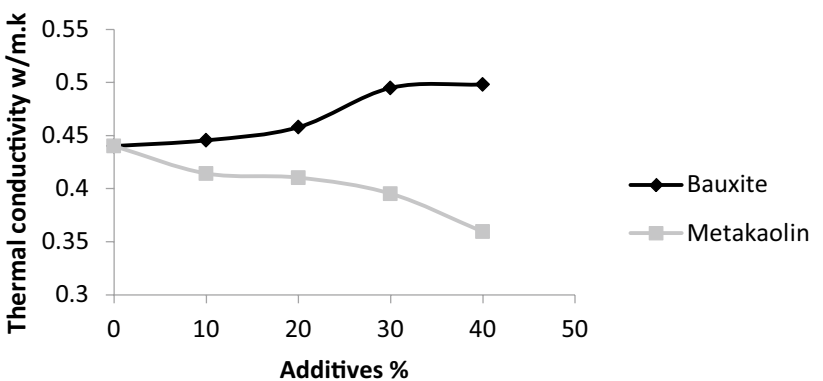

Fig. 10 Thermal conductivity of refractory specimens with different bauxite and metakaolin additions

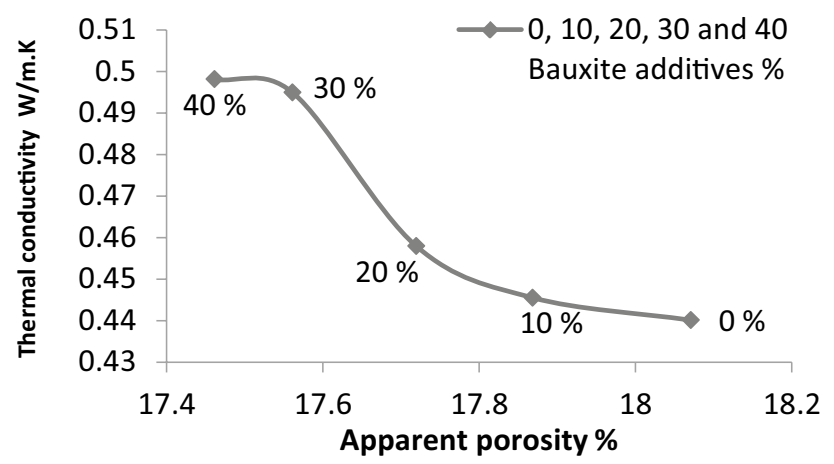

Fig. 11 Relation between thermal conductivity and porosity of refractory specimens with different bauxite additions

unit volume is negligibly small compared with that of the solid phase in a material [12].

\subsection{Thermal diffusivity}

The change in thermal diffusivity with increasing the addition of bauxite and metakaolin is shown in Fig. 16. The results showed that the thermal diffusivity values decrease

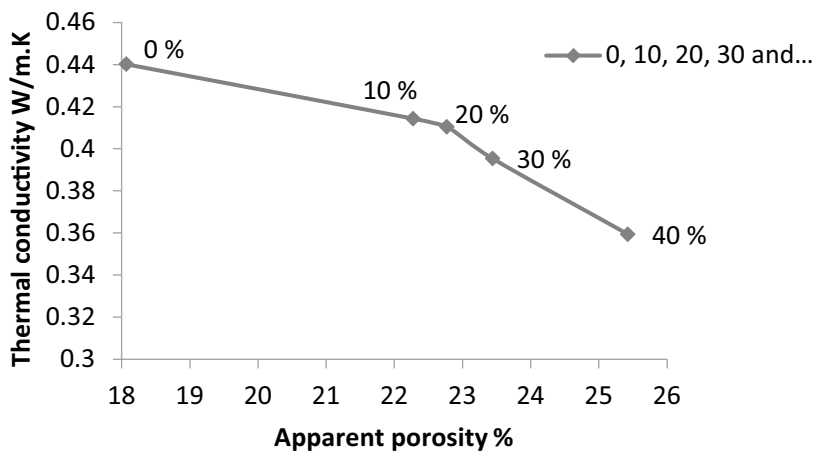

Fig. 12 Relation between thermal conductivity and porosity of refractory specimens with different metakaolin additions

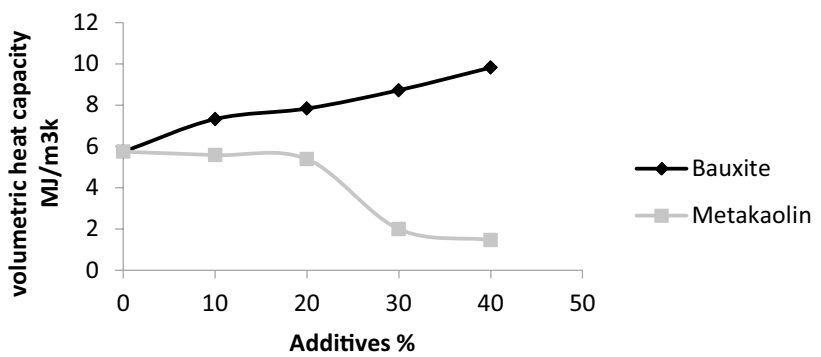

Fig. 13 Volumetric heat capacity of refractory specimens with different bauxite and metakaolin additions

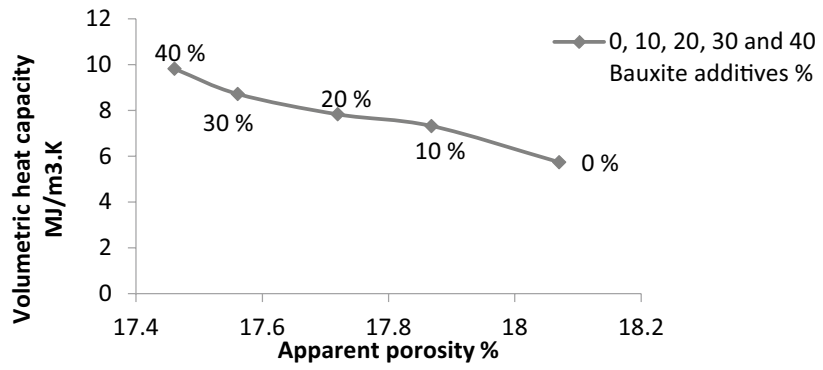

Fig. 14 Relation between volumetric heat capacity and porosity of refractory specimens with different bauxite additions

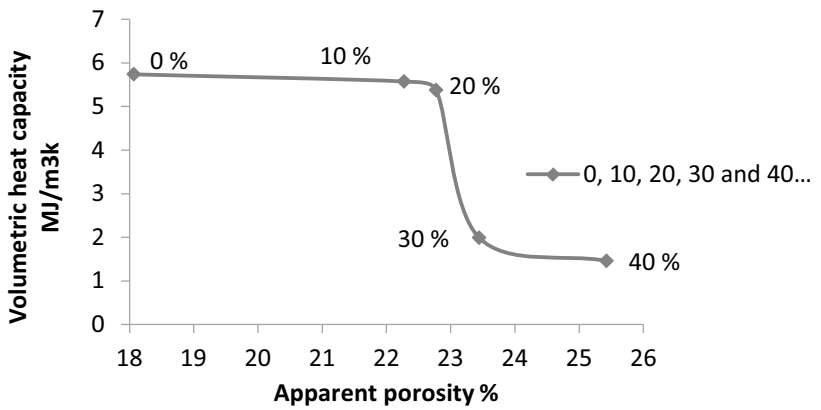

Fig. 15 Relation between volumetric heat capacity and porosity of refractory specimens with different metakaolin additions 


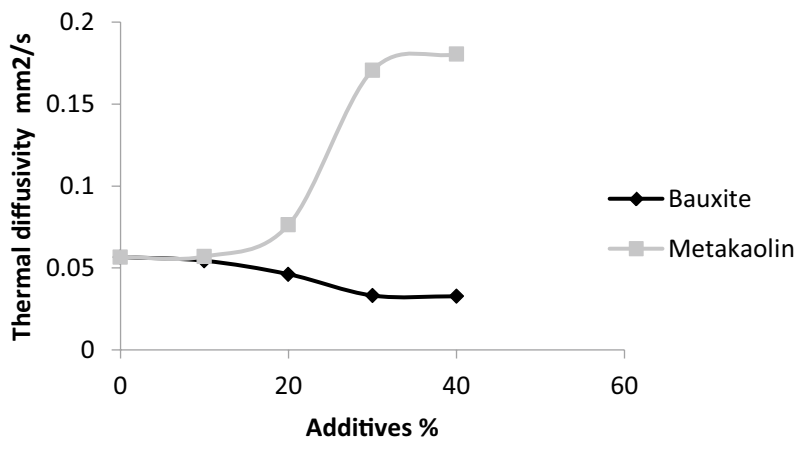

Fig. 16 Thermal diffusivity of refractory specimens with different bauxite and metakaolin additions

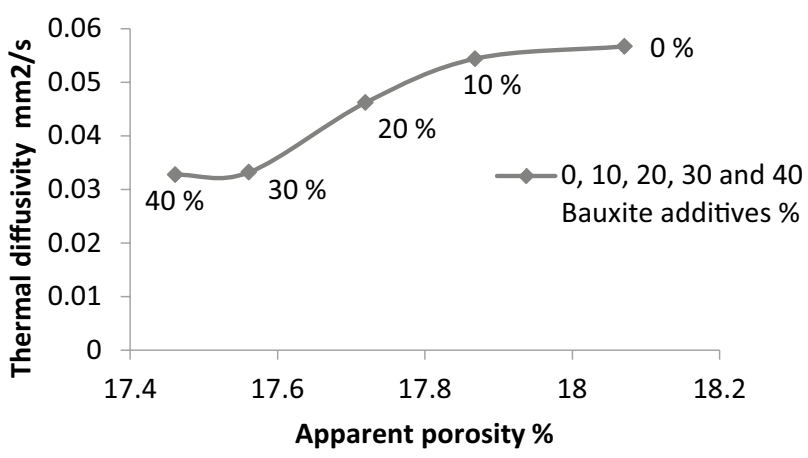

Fig. 17 Relation between thermal diffusivity and porosity of refractory specimens with different bauxite additions

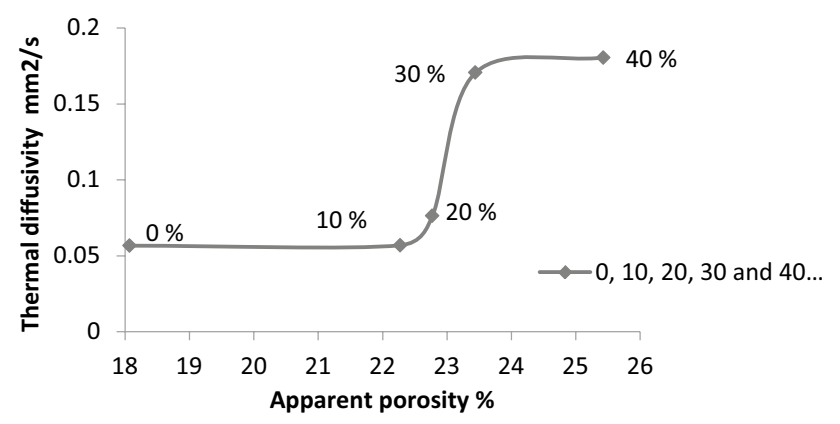

Fig. 18 Relation between thermal diffusivity and porosity of refractory specimens with different metakaolin additions

with addition bauxite, because it is affected by the high density which resulted with adding this material, because the diffusivity depends on the movement of molecules; therefore, the thermal diffusivity increases after adding metakaolin, because it forms a high porosity product. Figures 17 and 18 show the relation between thermal diffusivity and porosity. The coefficient of thermal diffusivity increases with an increase in the amount of additives. The thermal diffusivity of specimen without any additive was $0.07 \mathrm{~m}^{2} / \mathrm{s}$, which decreased by $57 \%$ for $40 \mathrm{wt} . \%$ bauxite additives and increased with porosity ranged from 17 to $18 \%$. As well as, the thermal diffusivity of specimen was increased by $67 \%$ for $40 \mathrm{wt} . \%$ metakaolin additives and increased with porosity ranged from 18 to $25.4 \%$.

The low thermal diffusivity values are required for minimizing heat conduction. The physical significance of low thermal diffusivity is associated with the low rate of change of temperature through the material during the heating process. The observed low values of the coefficient of thermal diffusivity in the present study demonstrated that the investigated samples are suitable for use as thermal insulators [13].

\section{Conclusion}

Depending on the experimental procedure and the carried out tests on different types of the prepared mortars, it concluded that the addition of bauxite and flint led to an increasing in density and decreasing in porosity ratio. The decrease in porosity of refractory products leads to increased thermal properties such as thermal conductivity and volumetric heat capacity by the addition of bauxite and flint, but the addition of metakaolin led to decrease them. Thermal diffusivity increased with increasing metakaolin additives, while it decreased with bauxite and flint additives. The addition of potassium silicate as a bonding material has improved physical properties due to the role of the potassium element in forming a perfect glass phase during the sintering process.

Open Access This article is distributed under the terms of the Creative Commons Attribution 4.0 International License (http://creativeco mmons.org/licenses/by/4.0/), which permits unrestricted use, distribution, and reproduction in any medium, provided you give appropriate credit to the original author(s) and the source, provide a link to the Creative Commons license, and indicate if changes were made.

\section{References}

1. C. Sadik, I. El Amrani, A. Albizane, New J. Glass. Ceram. 3, 59 (2013)

2. Refractories, The Refractories Institute, Pittsburgh, PA, USA (1987)

3. H.A. Christianto, Effect of chemical and mineral admixtures on the fresh properties of self compacting mortars, M.Sc. thesis, Middle East Technical University, (2004)

4. M. Al-Amaireh, Improving the physical and thermal properties of the fire clay refractory bricks produced from bauxite. J. Appl. Sci. 6(12), 2605-2610 (2006)

5. K. Andreev, S. Sinnema, A. Rkik, S. Allaoui, E. Blond, A. Gasser, Compressive behaviour of dry joints in refractory ceramic masonry. Constr. Build. Mater. 34, 402-408 
6. D.F. Mahdi, Preparation of refractory mortar from Iraqi raw materials. Iraqi J. Appl. Phys. 11(2), 37-40 (2015)

7. I. Torres, G. Matias, Sustainable mortars for rehabilitation of old plasters. Eng. Struct. (2016)

8. ASTM F1097-91, Standard specification for mortar, refractory (high-temperature, air-setting)

9. ASTM C 20, Standard test methods for apparent porosity, water absorption, apparent specific gravity, and bulk density of burned refractory brick and shapes by boiling water (2015)

10. International Standard,: ISO 22007-2, Plastics - determination of thermal conductivity and thermal diffusivity-part 2: transient plane heat source (hot disc) method (2008)
11. M.W. Barsoum, Fundamentals of Ceramics, Published by Institute of Physics UK, (2003) (ISBN 075030902 4)

12. I. Sumirat, Y. Ando, S. Shimamura, Theoretical consideration of the effect of porosity on thermal conductivity of porous materials. J Porous Mater. 13, 439-443 (2006)

13. S. Ahmada, Y. Iqbal, R. Muhammad, Effects of coal and wheat husk additives on the physical, thermal and mechanical properties of clay bricks. Bol. Soc. Esp. Cerám. Vidrio. 56 (2017) 131-138 